\title{
Estimation of Intervention Distances for Urgent Protective Actions Using Comparative Approach of MACCS and InterRAS
}

\author{
Mazzammal Hussain, ${ }^{1}$ Salah Ud-Din Khan, ${ }^{2}$ \\ Waqar A. Adil Syed, ${ }^{1}$ and Shahab Ud-Din Khan ${ }^{3}$ \\ ${ }^{1}$ Department of Physics, Faculty of Basic and Applied Sciences, International Islamic University, H-10, Islamabad 44000, Pakistan \\ ${ }^{2}$ Deanship of Scientific Research, College of Engineering, King Saud University, P.O. Box 800, Riyadh 11421, Saudi Arabia \\ ${ }^{3}$ Tokamak Design Division, Institute of Plasma Physics, Chinese Academy of Sciences, 350 Shushanhu Road, Hefei, \\ Anhui 230031, China
}

Correspondence should be addressed to Salah Ud-Din Khan; drskhan@ksu.edu.sa

Received 19 January 2014; Revised 1 April 2014; Accepted 3 May 2014; Published 28 May 2014

Academic Editor: Inn Seock Kim

\begin{abstract}
Copyright (C) 2014 Mazzammal Hussain et al. This is an open access article distributed under the Creative Commons Attribution License, which permits unrestricted use, distribution, and reproduction in any medium, provided the original work is properly cited.

Distances for taking evacuation as a protective measure during early phase of a nuclear accident have been approximated using MELCOR Accident Consequence Code System (MACCS). As a reference data, the source term of Pakistan Research Reactor 1 (PARR-1) and meteorological data of Islamabad, Pakistan, have been considered. Based on comparison with published data and international radiological assessment (InterRAS) code results, it is concluded that MACCS is a rational tool for estimation of urgent protective actions during early phase of nuclear accident by taking into account the variations in meteorological and release concentrations parameters.
\end{abstract}

\section{Introduction}

A range of probable accidents are associated with nuclear power plants starting with minor incident to immense disaster. Different researchers had used MACCS code to analyze the nuclear power plants accident consequences. Jongtae Jeong and Wondea Jung studied estimation of early health effects for different combinations of release parameters and meteorological data using MACCS code for Younggwang 3 and 4 nuclear power plants in Korea concluding that, with the same amount of radioactive material released to the atmosphere, a large difference in early health effects from case to case was observed [1]. Haste and coworkers attempted to demonstrate a MELCOR-MACCS capability to simulate the accident scenarios for the whole plant, including the containment response and off-site consequences arising from fission product release from the containment. The results provided a good basis for the NPP analysis foreseen [2]. Ke-Shih performed reevaluation of emergency planning zones (EPZs) for nuclear power plants (NPPs) using MACCS2 code and concluded that the radius identified previously is a reasonable conservative value of EPZs for each of the three operating NPPs in Taiwan [3]. Jeong and Ha studied influence of source term release parameters on health effects for Younggwang 3 and 4 nuclear power plants in Korea using MACCS code and concluded that the research work will be very useful for developing strategies for reducing off-site consequences of accident management if they are combined with influence of weather conditions [4]. Thaning and Baklanov considered a simulated accident at a nuclear power plant that could cause a large release of radioactivity into the atmosphere. The consequence analysis was performed using a 3-dimensional mesoscale model and MACCS code [5].

\section{Research Methodology}

2.1. Computational Technique: MACCS Code. Sandia National Laboratories developed MELCOR Accident Consequence Code System (MACCS) for the consequence assessment of 


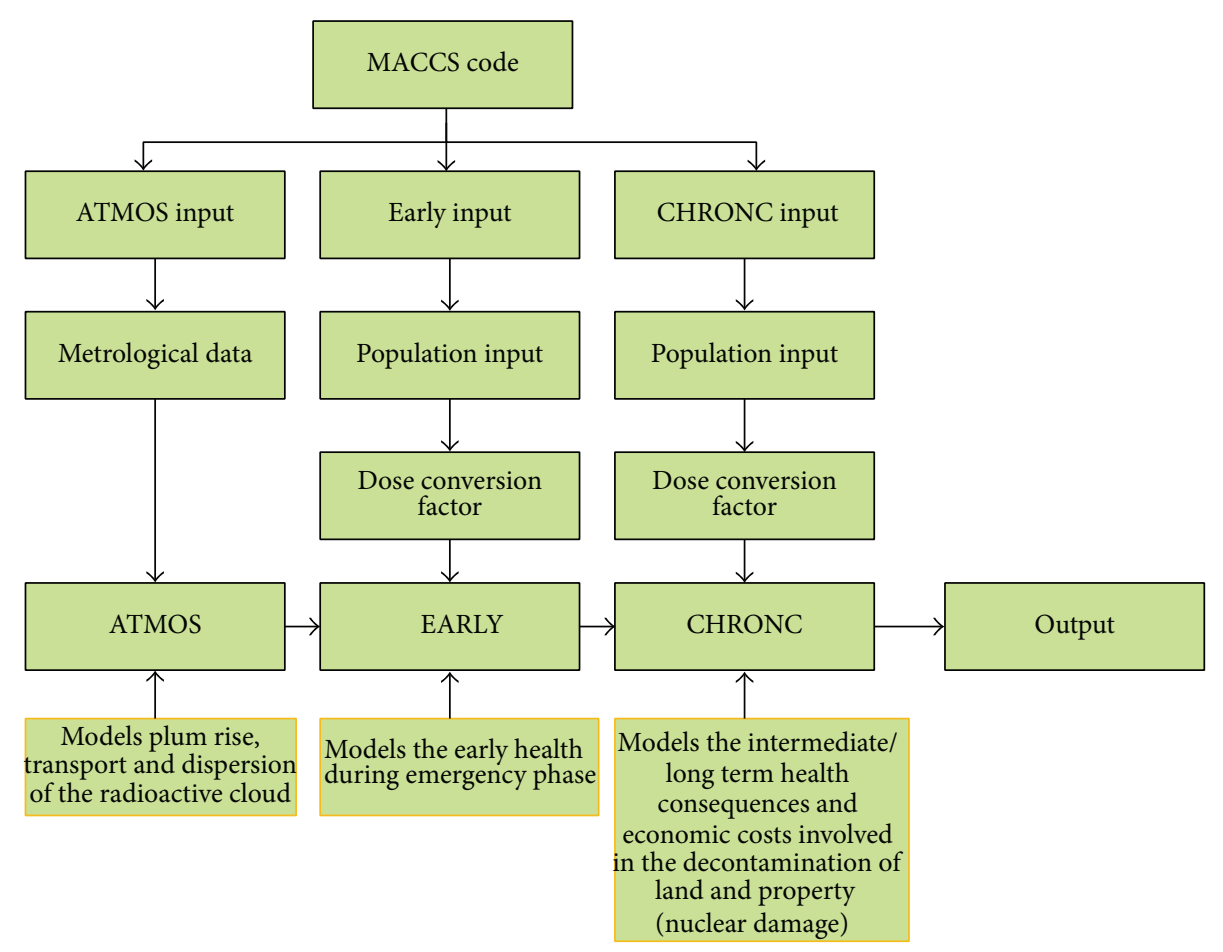

FIgURE 1: Flow diagram of MACCS code.

severe accidents at nuclear power plants. MACCS is organized into three modules, the ATMOS module which performs the atmospheric transport and deposition portion of the calculation, the EARLY module which estimates the consequences of the accident immediately after the accident usually within the first week, and the CHRONC module which estimates the long term consequences of the accident. The flow diagram of MACCS code [6-8] is shown in Figure 1.

In MACCS code, Gaussian plume model has been used for the study of atmospheric dispersion of radioactive material and vertical and crosswind distributions. The plume dimensions are defined in vertical and crosswind direction by the standard deviations $\left(\sigma_{y}, \sigma_{z}\right)$ of the normal distribution of material concentration in crosswind and vertical directions. The general form of the Gaussian plume equation is

$$
\begin{aligned}
\chi(x, y, z)= & \frac{Q}{2 \pi \bar{u} \sigma_{y} \sigma_{z}} \\
& \times \exp \left[-\frac{1}{2}\left(\frac{y}{\sigma_{y}}\right)^{2}\right] \exp \left[-\frac{1}{2}\left(\frac{z-h}{\sigma_{z}}\right)^{2}\right],
\end{aligned}
$$

where $\chi(x, y, z)$ is the time integrated air concentration (Bq$\left.\mathrm{s} / \mathrm{m}^{3}\right)$ at the downwind location $(x, y, z), \mathrm{Q}$ is the source strength $(\mathrm{Bq}), \bar{u}$ is the mean downwind speed, $\sigma_{y}$ and $\sigma_{z}$ are the standard deviations $(\mathrm{m})$ of the normal concentration distribution along crosswind and vertical direction, and $h$ is the release height $(\mathrm{m})$.

Equation (1) is not applicable when plume expands vertically and is bounded by mixing layer or by the ground. To solve this problem, ground and mixing layers are considered as totally reflecting boundaries. This is achieved by adding a mirror image source below the ground and above the inversion layer. By considering this effect in (1), the centerline air concentration $\chi(x=0, y=0, z=H)$ and ground concentrations $\chi(x=0, y=0, z=0)$, after time of release to the time at which the concentrations become uniform along vertical direction, are given by

$$
\begin{aligned}
& \chi(x, y=0, z) \\
& =\frac{Q}{2 \pi \sigma_{y} \sigma_{z} \bar{u}}\left[\exp \left[-\frac{1}{2}\left(\frac{z-H}{\sigma_{z}}\right)^{2}\right]\right. \\
& +\exp \left[-\frac{1}{2}\left(\frac{z+H}{\sigma_{z}}\right)^{2}\right] \\
& +\sum_{n=1}^{5}\left\{\exp \left[-\frac{1}{2}\left(\frac{z-H-2 n L}{\sigma_{z}}\right)^{2}\right]\right. \\
& +\exp \left[-\frac{1}{2}\left(\frac{z+H-2 n L}{\sigma_{z}}\right)^{2}\right] \\
& +\exp \left[-\frac{1}{2}\left(\frac{z-H+2 n L}{\sigma_{z}}\right)^{2}\right] \\
& \left.\left.+\exp \left[-\frac{1}{2}\left(\frac{z+H+2 n L}{\sigma_{z}}\right)^{2}\right]\right\}\right] \text {, }
\end{aligned}
$$

where $H=(h+\Delta h)$ is the height of the plume centerline $(\mathrm{m})$, the initial release height of the plume before plume rise $(\mathrm{m})$, 
$\Delta h=$ the amount of plume rise $(\mathrm{m})$, and $L=$ the height $(\mathrm{m})$ of the inversion layer (mixing height).

In MACCS, only first five terms are considered and the rest of the terms are neglected. When a uniform vertical distribution is attained, the following equation is used to calculate centerline air concentration:

$$
\chi(x, y=0, z)=\frac{Q}{\sqrt{2 \pi} \bar{u} \sigma_{y} L} .
$$

For the estimation of radiation doses during early phase of nuclear emergency, the following pathways are taken into consideration:

(i) external and internal exposure from cloud shine,

(ii) exposures from ground shine,

(iii) internal exposure from resuspension inhalation and skin doses from deposited material onto the skin,

(iv) acute and lifetime doses from early exposures.

2.2. Meteorological Conditions. For the execution of MACCS code, the hourly-based data for the year 2010 of Islamabad collected from the ground station (with an approximate height of 10 meters) has been used. As the near surface wind speed increases with altitude, the same data if used for the stake height $(61 \mathrm{~m})$ will overestimate the plume rise. This could produce significant underestimation of the radiation doses. To incorporate the effect of wind speed $(\mathrm{m} / \mathrm{s})$ with altitude, the following theoretical formula was used to estimate the wind speed at higher altitudes:

$$
u=u_{o}\left(\frac{z}{z_{o}}\right)^{p}
$$

where $u=$ wind speed at height $z(\mathrm{~m} / \mathrm{s}), u_{o}=$ wind speed at surface $(\mathrm{m} / \mathrm{s})$, and $p=$ parameter (dimensionless) that varies with stability class and surface roughness.

The wind rose for the reported year is presented in Figure 2. The percentage value of wind direction remained $3.7 \%$ in north, $8.7 \%$ in northeast, $8.4 \%$ in east, $13.8 \%$ in southeast, $10.8 \%$ in south, $38.3 \%$ in southwest, $6.4 \%$ in west, and $10 \%$ in northwest, respectively. Data presented in Figure 2 represents that dominant wind direction was southwest (38.3\%) during year 2010. The dominant atmospheric stability class as presented in Figure 3 was stability class-F.

\section{Initial Conditions and Assumptions}

3.1. Source Term and Release Fraction. The source term for the fission product in the reactor core was taken from the international published data [6] for a postulated accidental airborne release from Pakistan Research Reactor 1 (PARR-1), Islamabad, on upgraded power of $10 \mathrm{MW}$. The fractions of releases were based on USNRC document NUREG-1150. The release fractions of $1,0.4,0.3,0.05$, and 0.02 for noble gases, halogens, alkali metals, the tellurium group, and the $\mathrm{Ba}-\mathrm{Sr}$ group, respectively, have been considered.

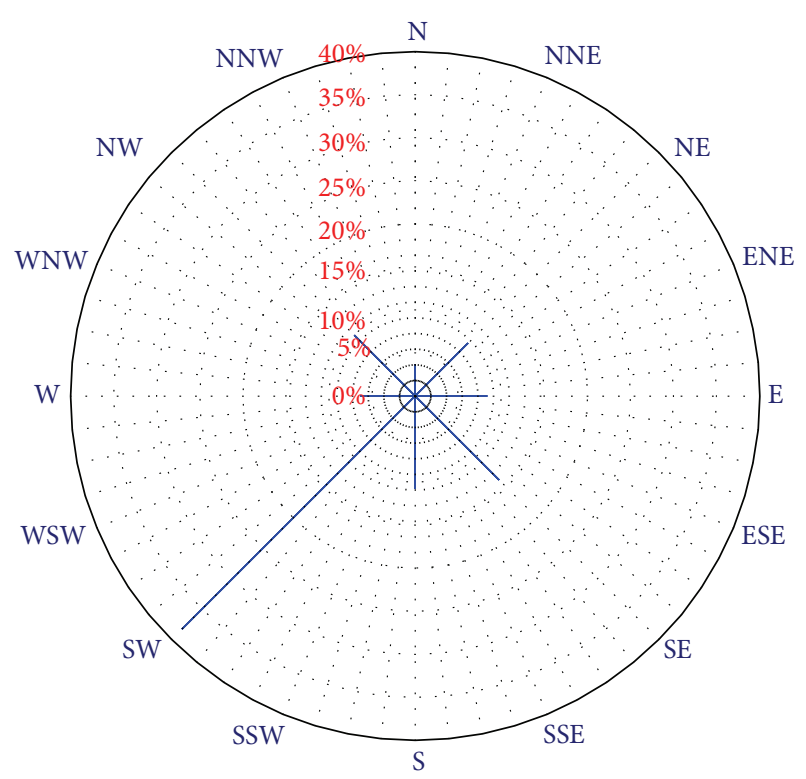

$\square$ Series 1

Figure 2: Wind rose for sixteen directions.

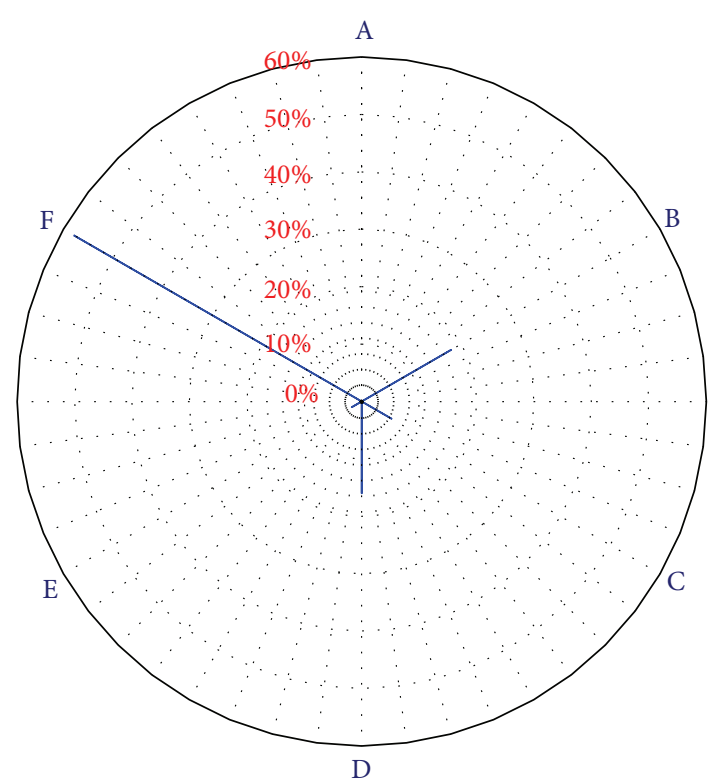

Figure 3: Dominant stability class.

3.2. Meteorological Options. MACCS code provides different options for the selection of the meteorological data. The following four meteorological options (MO) have been used to estimate the radiation doses:

(i) MO-1: user specified day and hour,

(ii) MO-2: weather bin sampling,

(iii) MO-3: constant weather boundary data,

(iv) MO-4: special case (maximum wind speed). 


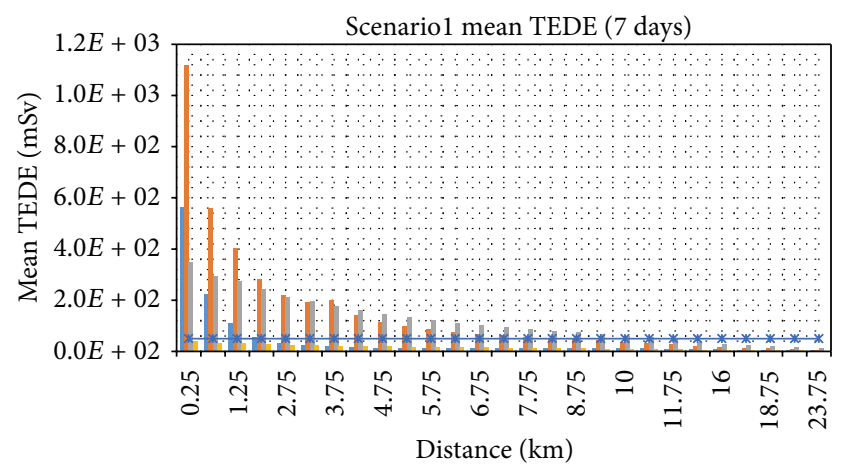

User specified day and hour

Weather bin sampling

Constant boundary weather data

Special case (maximum velocity)

*-Reference level for evacuation

Figure 4: Scenario 1 mean TEDE (7 days).

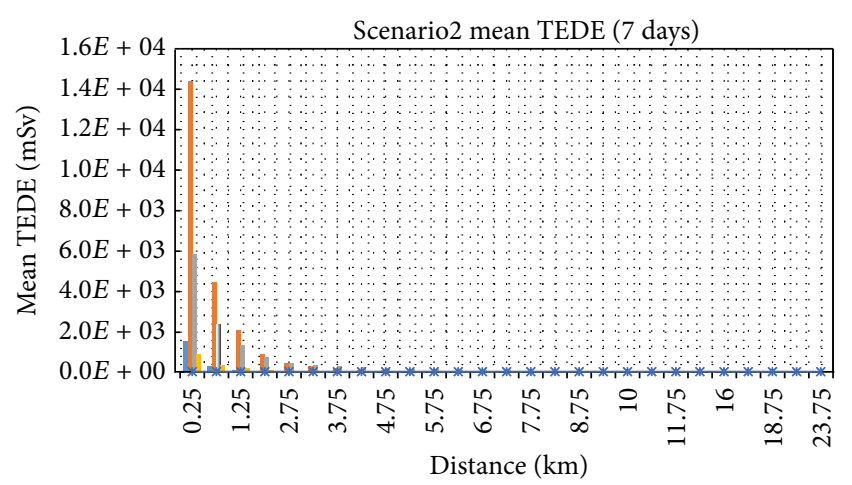

\footnotetext{
User specified day and hour

Weather bin sampling

Constant boundary weather data

Special case (maximam velocity)

* Reference level for evacuation
}

FIgURE 5: Scenario 2 mean TEDE (7 days).

\subsection{Release Scenarios}

Scenario 1. In this scenario, the releases and meteorological data have been considered at height of 61 meters (stake releases). The total effective dose equivalent (TEDE) for whole body modeled using four different meteorological options is presented in Figure 4.

Scenario 2. In this scenario, the releases and meteorological data have been considered at ground level $(10 \mathrm{~m})$. The TEDE for whole body modeled by using four different meteorological options is presented in Figure 5.

3.4. Comparison of Doses for Constant Weather Condition. The comparison of radiation doses of the scenarios has been made with the literature data (using the meteorological

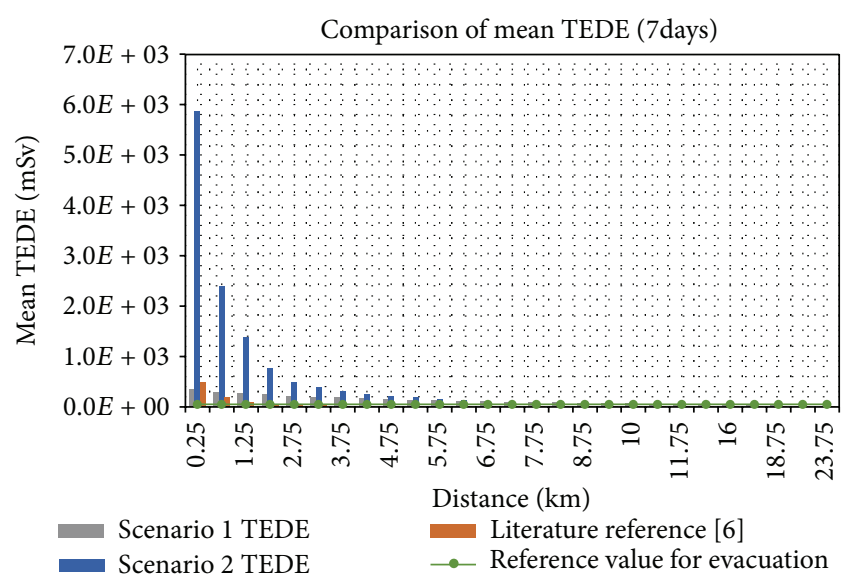

FIGURE 6: Comparison of mean TEDE (7 days) for constant weather.

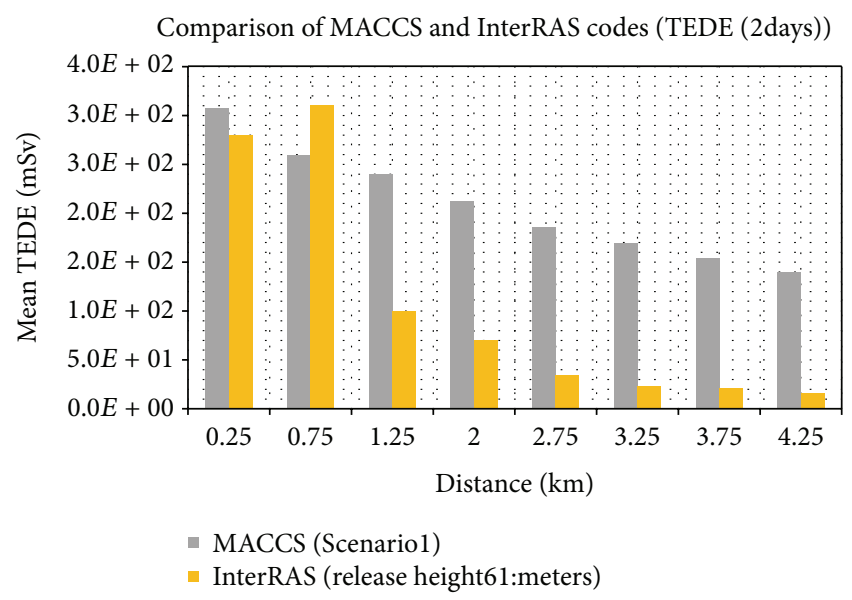

FIgURE 7: Comparison of MACCS and InterRAS codes.

conditions of the site [6]) for 61-meter height using constant weather conditions. The comparison is presented in Figure 6.

\section{Comparison of MACCS and InterRAS Codes}

Comparison of MACCS code with InterRAS code $[9,10]$ for releases at the height of 61 meters using constant weather conditions has been made. The InterRAS code estimate radiation doses maximum up to 48 hours. The doses estimated using InterRAS code are comparable to doses estimated using MACCS code. The comparison of MACCS and InterRAS code results is presented in Figure 7.

4.1. Mean TEDE Trends (One Week). Mean TEDE for different release heights and meteorological conditions has been analyzed and presented in Figures 4-6. Through analysis, it was found that radiation doses reduce exponentially over the distance.

It was found that the protective action "evacuation" was required at different distances in different accident situations. The radiation doses fall below the intervention level for 
TABLE 1: Evacuation intervention distance for different MET options.

\begin{tabular}{lcccc}
\hline Scenarios & \multicolumn{4}{c}{ Intervention (evacuation) distances $(\mathrm{Km})$} \\
& MO-1 & MO-2 & MO-3 & MO-4 \\
\hline Scenario 1 & 2.00 & 7.75 & 10.00 & 0.25 \\
Scenario 2 & 2.75 & 6.75 & 10.75 & 4.75 \\
Literature [6] & - & - & 2.75 & - \\
\hline
\end{tabular}

evacuation ( $50 \mathrm{mSv})$ at 10 kilometers for Scenario 1, 10.75 kilometers for Scenario 2, and 2.75 kilometers for constant weather condition using site specific data.

4.2. Mean Distance for Intervention Levels. The intervention level for evacuation $(50 \mathrm{mSv})$ was achieved at different distances for different emergency scenarios and for different meteorological options. Mean distances (Km) for taking intervention (evacuation) for different meteorological options (MO) are presented in Table 1.

A comparison of MACCS and InterRAS code output results (mean effective dose equivalent to whole body for two days) for constant weather conditions has been presented in Figure 7. From the trend analysis, it is found that the maximum of $5.10 \times 10^{3} \mathrm{mSv}$ has been observed at mean distance of $0.25 \mathrm{~km}$. At the nearby distances, the doses estimated using InterRAS code are comparable to doses estimated using MACCS code.

\section{Summary and Conclusion}

The most frequent wind direction southwest, that is, $38.3 \%$, and the prevailing stability class $\mathrm{F}$, that is, $58.16 \%$, were recorded during year 2010. Intervention distance for evacuation remained in the range 2.0 to 2.75 kilometers for user specified MET data; 6.75 to 7.75 kilometers for weather bin sampling method; 2.75 to 10.75 kilometers for constant weather data; and 0.25 to 4.75 kilometers for maximum wind speed. With site specific meteorological conditions, intervention distance range is very low, that is, 2.0 to 2.75 kilometers, which is very close to the already published value, that is, 1 to 2 kilometers, using "InterRAS" code.

The seven-day TEDE has been modeled and compared with the reference levels [11] for evacuation, that is, $50 \mathrm{mSv}$ for not more than seven days. It is found that the protective action "evacuation" was required at different distances in different accident scenarios.

MACCS code during early phase of nuclear emergency reasonably estimates the radiation doses by taking into account the variation in meteorological data, release duration, and concentrations. MACCS code could be an efficient tool to be used during early phase of nuclear emergencies if integrated with pre- and postprocessor for handling and presentation of data.

\section{Conflict of Interests}

The authors declare that there is no conflict of interests regarding the publication of this paper.

\section{Acknowledgment}

The authors would like to extend their sincere appreciation to the deanship of scientific research at King Saud University for its funding of this research through research group Project no. RGP VPP-255.

\section{References}

[1] J. Jeong and W. Jung, "The estimation of early health effects for different combinations of release parameters and meteorological data," Journal of Korean Nuclear Society, vol. 33, no. 6, pp. 557-565, 2001.

[2] T. Haste, J. Birchley, E. Cazzoli, and J. Vitazkova, "MELCOR/MACCS simulation of the TMI-2 severe accident and initial recovery phases, off-site fission product release and consequences," Nuclear Engineering and Design, vol. 236, no. 10, pp. 1099-1112, 2006.

[3] J. Wu, Y. Yang, I. Chen, H. Chen, and K. Chuang, "Reevaluation of the emergency planning zone for nuclear power plants in Taiwan using MACCS2 code," Applied Radiation and Isotopes, vol. 64, no. 4, pp. 448-454, 2006.

[4] J. Jeong and J. Ha, "The influence of source term release parameters on health effects," Journal of The Korean Nuclear Society, vol. 31, no. 3, pp. 294-302, 1999.

[5] L. Thaning and A. Baklanov, "Simulation of the atmospheric transport and deposition on a local/meso- and regional scale after hypothetical accidents at the Kola nuclear power plant," Science of the Total Environment, vol. 202, no. 1-3, pp. 199-210, 1997.

[6] "MELCOR Accident Consequence Code System (MACCS)," User's Guide, NUREG/CR-4691-Vol. 1.

[7] "MELCOR Accident Consequence Code System (MACCS)," Model Description, NUREG/CR-4691-Vol. 2.

[8] "MELCOR Accident Consequence Code System (MACCS)," Programmer's Reference Manual, NUREG/CR-4691-Vol. 3.

[9] C. Lin and L. Peng, "Study of interRAS application in early radiation consequences assessment of attacked nuclear power plant," in Proceedings of the 11th China Symposium on Computer Application in Modern Science and Technology, pp. 105-108, Beijing, China, 2003.

[10] M. Hussain, S. U. Khan, and W. A. Syed, "Estimation of emergency planning zones for nuclear research reactor using plume dispersion code," in Proceedings of the 20th International Conference on Nuclear Engineering Collocated with the ASME, Power Conference (ICONE20-POWER '12), pp. 479-483, Anaheim, Calif, USA, July-August 2012.

[11] "Regulations on Management of a Nuclear or Radiological Emergency-PAK/914," 2008. 


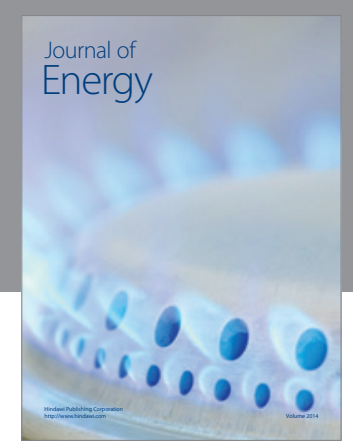

Journal of

Industrial Engineering
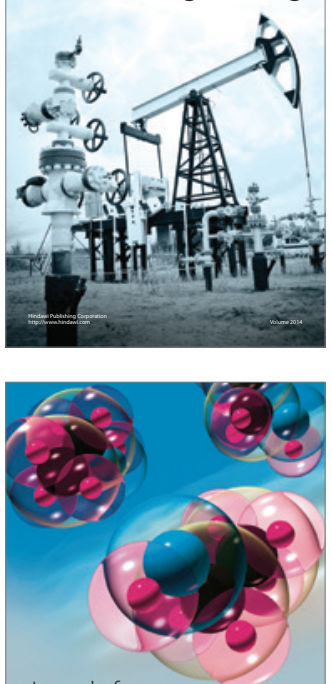

Fuels
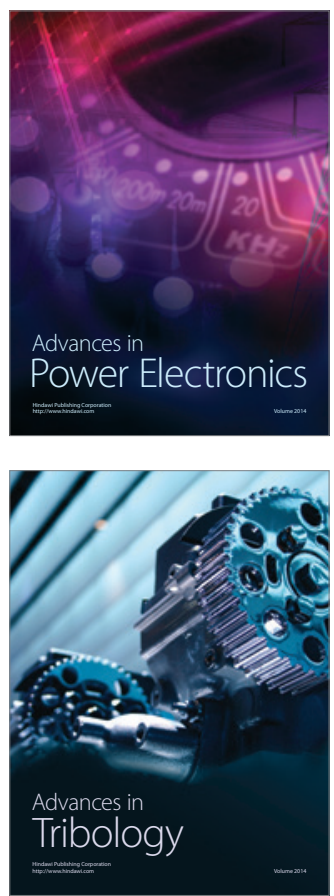

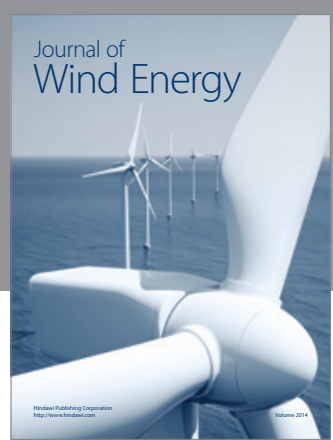

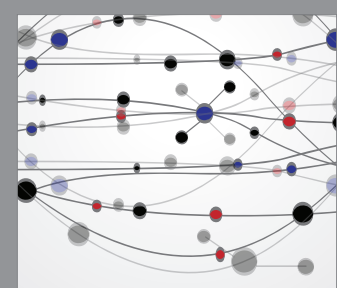

The Scientific World Journal

Submit your manuscripts at http://www.hindawi.com

Journal of

Structures
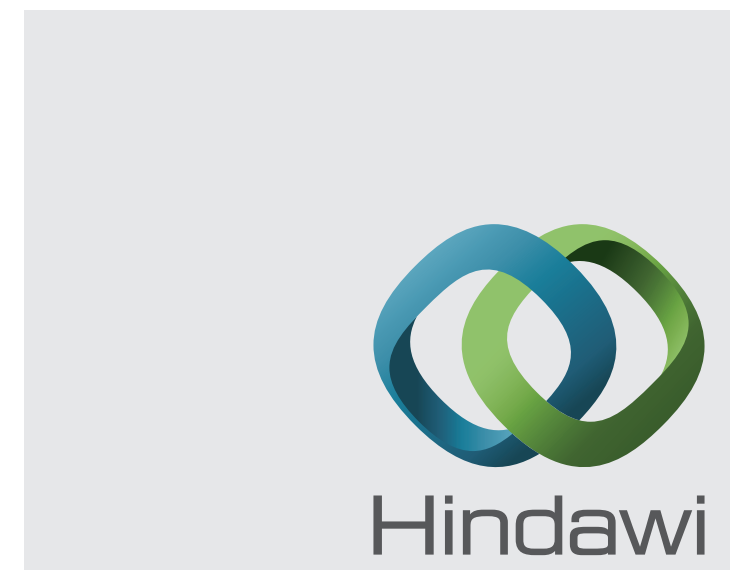

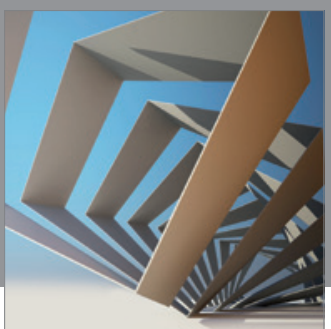

Rotating

Machinery
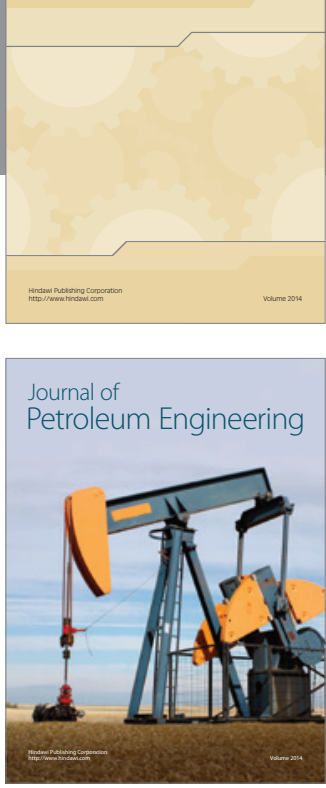

Journal of

Solar Energy
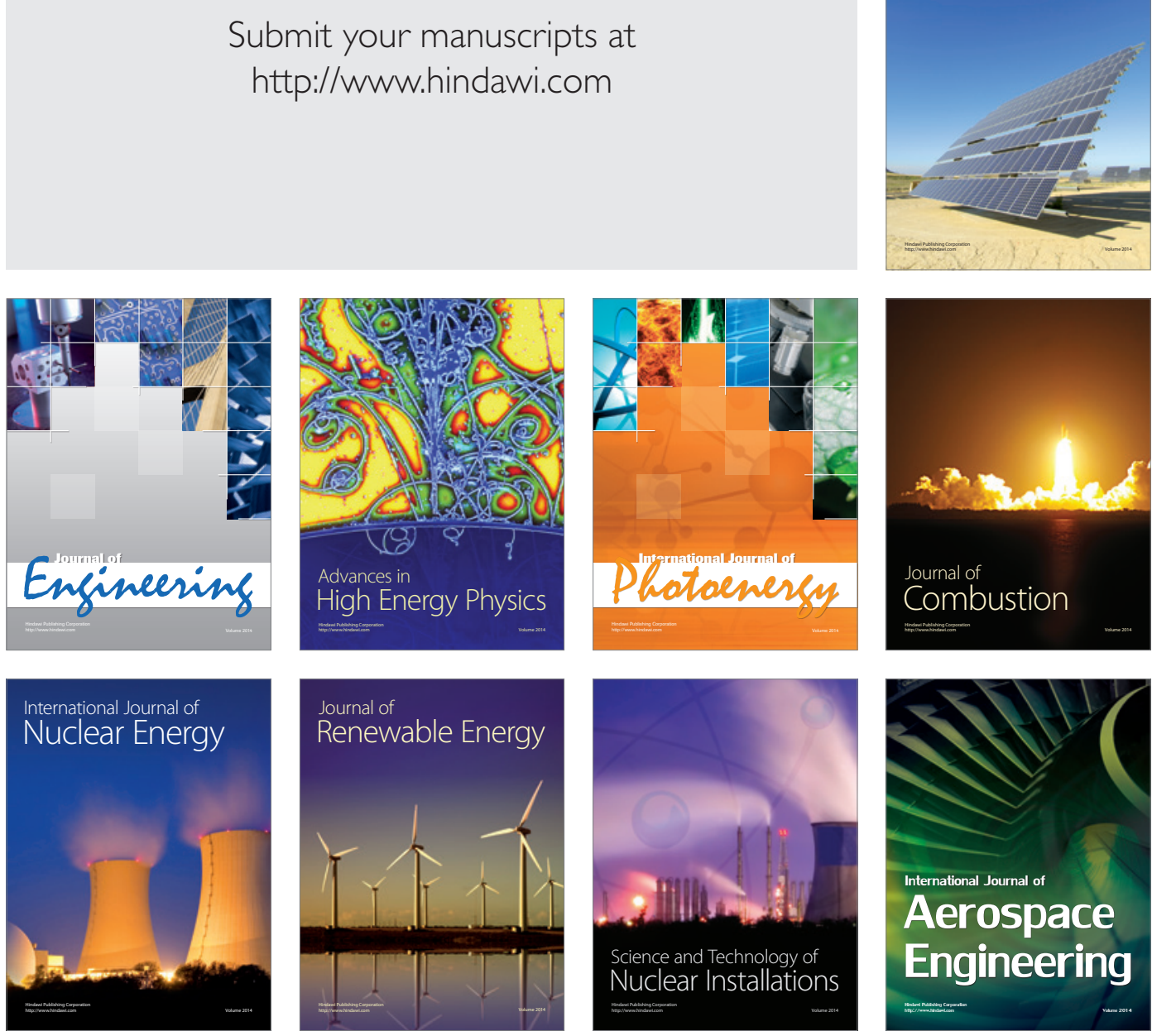